\title{
Publisher Correction: Accurate and stable timekeeping
}

\section{Andrei Derevianko (i)}

Nature Reviews Physics (2019) https://doi.org/10.1038/s42254-019-0089-4 Published online 29 July 2019

This article was originally published with an incorrect reference to the work of Oelker et al. in Nature Photonics. Reference 2 in the article and the 'Refers to' citation should read: Oelker E. et al. Demonstration of $4.8 \times 10^{-17}$ stability at $1 \mathrm{~s}$ for two independent optical clocks. Nat. Photon. https://doi.org/10.1038/s41566-019-0493-4 (2019). This error has been corrected in the HTML and PDF versions of the article.

We apologize to readers for this error.

https://doi.org/10.1038/s42254-019-0103-x I Published online 9 August 2019 